PALABRAS CLAVE

Política comercial

Reforma económica

Exportaciones

Crecimiento económico

Análisis económico

Métodos de simulación

Modelos matemáticos

América Centra

Costa Rica

Honduras

El Salvador
Marco V. Sánchez

Oficial de Asuntos Económicos,

División de Políticas de Desarrollo y

Análisis, Departamento de Asuntos

Económicos y Sociales

Naciones Unidas

- sanchez-cantillo@un.org

\section{Apertura comercial y pobreza en Centroamérica: logros y desafíos}

\author{
Marco V. Sánchez
}

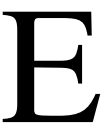

n las dos últimas décadas, en América Latina se han reformado los regímenes comerciales para facilitar el crecimiento centrado en las exportaciones, con la esperanza de que este tendría un "efecto de derrame" en favor de los más pobres. Este objetivo se ha logrado en distinta medida y su consecución ha dependido no solo de la eficacia de las reformas de la política comercial, sino también de la política cambiaria, de las perturbaciones externas y de las remesas de los trabajadores migrantes. El cambio tecnológico también ha sido fundamental para capitalizar los beneficios de las reformas. Estas afirmaciones se basan en los resultados de las simulaciones de un modelo de equilibrio general computable que se resolvió con datos de Costa Rica, El Salvador y Honduras. El modelo se combinó con una metodología de microsimulación de modo de captar plenamente las consecuencias distributivas de las políticas y de las crisis externas simuladas. 


\section{I}

\section{Introducción}

Una vez superada la crisis de la deuda y estabilizada la economía, en la mayoría de los países latinoamericanos se inició un proceso de reformas económicas que, entre otras medidas, supuso la implementación acelerada de una serie de reformas de la política comercial. Estas consistieron principalmente en la liberalización de las importaciones y el fomento explícito de las exportaciones para aprovechar las ventajas comparativas en la agricultura y en algunos sectores de la industria manufacturera. Con ello se esperaba alcanzar un rápido crecimiento centrado en las exportaciones que, en última instancia, se traduciría en una disminución de la pobreza.

Aunque en la mayoría de los países latinoamericanos se optó por introducir reformas bastante similares en los regímenes comerciales, en muchos casos su trayectoria con respecto al crecimiento centrado en las exportaciones y la pobreza ha sido divergente. En este documento se sostiene que se han alcanzado los objetivos de las reformas en los países que, por una parte, han logrado mantener un tipo de cambio real competitivo y relativamente estable $\mathrm{y}$, por otra, han incrementado la productividad. Se considera aquí que las perturbaciones externas, provocadas por las fluctuaciones de los precios mundiales y la afluencia masiva de capitales y de remesas de los trabajadores migrantes, han obstaculizado la estabilización del tipo de cambio real y la competitividad en algunos países. Además, pese a que el menor precio de las importaciones y el aumento de las corrientes de inversión extranjera directa han sido fundamentales para estimular el incremento de la productividad en los períodos de reforma de la política comercial, estos avances se han materializado solamente en los países en que la mano de obra calificada es relativamente abundante y en que hay sectores de exportación modernos y diversificados.

Lo sostenido en este trabajo se comprueba mediante la información disponible sobre tres países centroamericanos - Costa Rica, El Salvador y Honduras_- específicamente la combinación de los resultados de simulaciones de un modelo de equilibrio general computable resuelto con datos de dichos países e información sobre las tendencias registradas en el período 1990-2003. El análisis del modelo de equilibrio general computable se complementó con una metodología de microsimulación para captar la totalidad de las consecuencias distributivas de la política y de las perturbaciones externas simuladas.

Además de esta introducción, el documento se estructura de la siguiente manera. En la sección II se describen las principales reformas de la política comercial realizadas y el desempeño socioeconómico de los tres países estudiados en el período 1990-2003. Los aspectos analíticos y metodológicos del trabajo se abordan en la sección III. En la sección IV se analizan los resultados de las simulaciones del modelo de equilibrio general computable, combinándolos con las tendencias observadas y, por último, las conclusiones y las repercusiones de política más importantes se resumen en la sección V.

II

\section{La reforma de la política comercial y el desempeño socioeconómico}

En las dos últimas décadas, Costa Rica, El Salvador y Honduras - al igual que el resto de Centroamérica — han

$\square \mathrm{El}$ autor agradece los valiosos comentarios de Ana Sojo, José Cuesta Matthew Hammill y Pablo Sauma a las versiones preliminares del presente trabajo. Las opiniones aquí expresadas son de su exclusiva responsabilidad y no reflejan necesariamente el punto de vista de las Naciones Unidas ni de sus Estados Miembros. promovido las exportaciones y liberalizado aceleradamente las importaciones a fin de lograr un crecimiento económico sostenido centrado en las exportaciones y, en última instancia, reducir la pobreza. Con este objetivo, se crearon regímenes de exportación especiales y se reestructuraron los procedimientos pertinentes. Ello supuso la utilización transitoria de certificados de crédito tributario para subsidiar 
las exportaciones no tradicionales, eximir a los productores de artículos de exportación del pago de impuestos a las importaciones de materias primas y bienes de capital y la eliminación gradual de las restricciones cuantitativas y las sobretasas a las importaciones, así como la simplificación de los trámites aduaneros. Además, los tres países han suscrito acuerdos de libre comercio con otras naciones, incluido el Tratado de Libre Comercio entre República Dominicana, Centroamérica y los Estados Unidos (CAFTARD), y son miembros activos de la Organización Mundial del Comercio (OMC). Todas estas reformas se han traducido en una marcada reducción de los impuestos al comercio internacional. No solo se han reducido de manera considerable los derechos arancelarios sobre las importaciones, sino que prácticamente se han eliminado los que gravan las exportaciones (véase el gráfico 1).

Los tres países estudiados han optado por introducir reformas bastante similares de la política comercial, pues de hecho han seguido el patrón general de política comercial que se aplica en América Latina. Sin embargo, su trayectoria en materia de crecimiento centrado en las exportaciones y pobreza ha sido diferente. Aunque las exportaciones han aumentado en los tres países (véase el cuadro 1), solo Costa Rica ha logrado un verdadero crecimiento basado en las exportaciones (Sánchez y Sauma, 2006). Si bien las exportaciones de El Salvador se expandieron considerablemente en la década de 1990, la industria de bienes no comerciables parece haber sido el principal motor del modesto crecimiento económico del país (Acevedo, 2004). El incremento de las exportaciones en Honduras fue menos dinámico (Cuesta y Sánchez, 2004).

La diversificación de las exportaciones ha sido una precondición del crecimiento centrado en ellas. Costa Rica ha incorporado una amplia gama de productos agrícolas y manufacturados, algunos de ellos fabricados por nacientes industrias de alta tecnología, a su oferta de exportaciones. También ha incrementado en forma excepcional las exportaciones no tradicionales, que representaron casi el 80\% de los bienes exportados en 2000-2003 (véase el cuadro 1) y que se envían a un número cada vez mayor de socios comerciales. Por otra parte, en Honduras y El Salvador la diversificación de las exportaciones no ha sido un objetivo primario, sino que han optado por desarrollar industrias de reintegro (drawback), más conocidas como

GRÁFICO 1

Costa Rica, El Salvador y Honduras: tasa impositiva nominal media efectiva sobre exportaciones e importaciones ${ }^{a}, 1990-2003$ (En porcentajes)

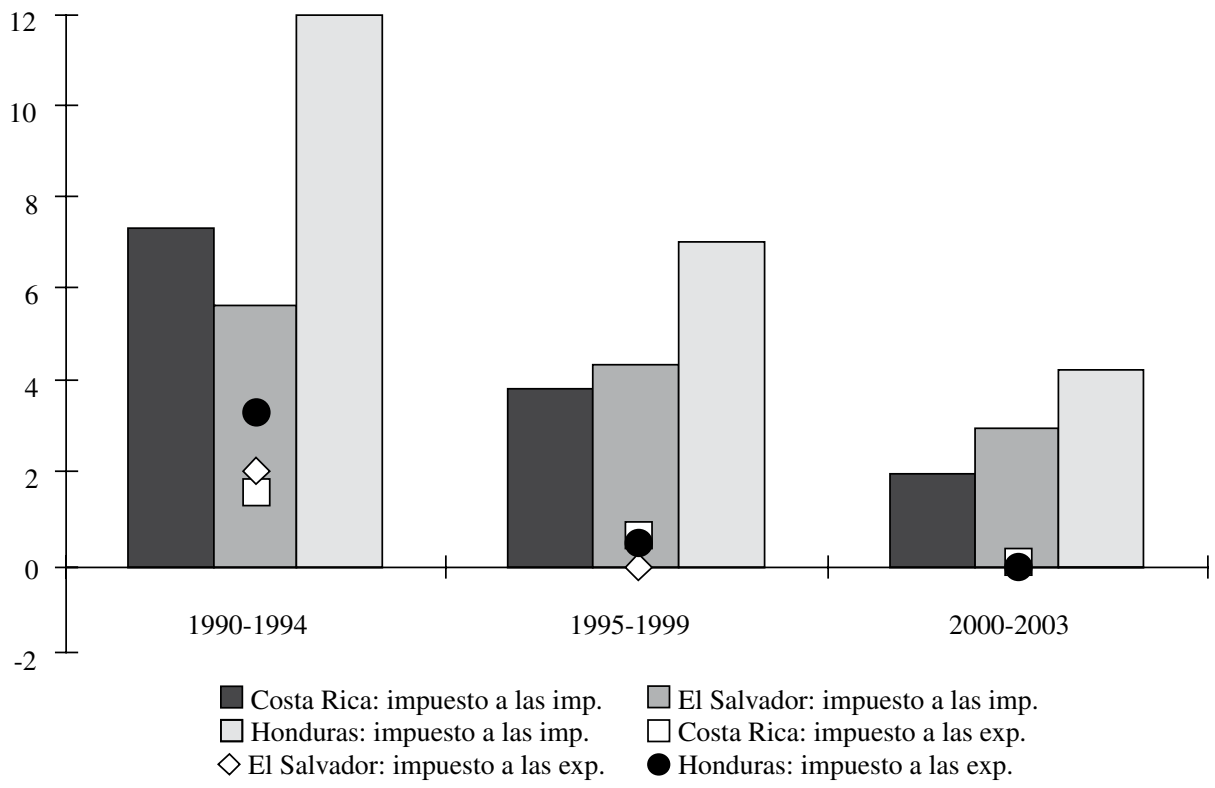

Fuente: elaboración propia sobre la base de datos de la Comisión Económica para América Latina y el Caribe (CEPAL).

a Ingresos por concepto de impuestos a las exportaciones e importaciones cobrados como parte de las exportaciones e importaciones de bienes, respectivamente, según valor. 
maquiladoras, que fabrican sobre todo productos textiles y prendas de vestir para la exportación, especialmente a los Estados Unidos. En 2000-2003, las exportaciones no tradicionales hondureñas no superaban el $45 \%$ de las exportaciones anuales de bienes, mientras que las de la industria maquiladora habían aumentado a más del $30 \%$ del total. Las exportaciones no tradicionales de El Salvador aumentaron, pero las del sector de la maquila han representado más de la mitad de las exportaciones de bienes desde 1999.
La liberalización del comercio ha estimulado las importaciones, pero, una vez más, la situación difiere de un país a otro (véase el cuadro 1). Las importaciones de materias primas y bienes de capital han aumentado en forma sistemática en Costa Rica, pues el crecimiento de las exportaciones ha incrementado su capacidad de generar divisas. En los otros dos países, en particular El Salvador, las importaciones de insumos intermedios para la maquila han aumentado de manera vertiginosa $y$, por este motivo, las exportaciones netas de dicha industria

CUADRO 1

Costa Rica, El Salvador y Honduras: indicadores macroeconómicos, 1990-2003

(Promedio anual del período de referencia)

\begin{tabular}{|c|c|c|c|c|}
\hline Indicador & País & 1990-1994 & 1995-1999 & $2000-2003$ \\
\hline Empleo (tasa de crecimiento anual) & $\begin{array}{l}\text { Costa Rica } \\
\text { El Salvador } \\
\text { Honduras }\end{array}$ & $\begin{array}{l}2,8 \\
7,6 \\
4,6\end{array}$ & $\begin{array}{l}2,8 \\
3,1 \\
5,2\end{array}$ & $\begin{array}{r}6,3 \\
3,8 \\
-0,5\end{array}$ \\
\hline $\begin{array}{l}\text { Exportaciones de bienes y servicios } \\
\text { (tasa de crecimiento anual) }\end{array}$ & $\begin{array}{l}\text { Costa Rica } \\
\text { El Salvador } \\
\text { Honduras }\end{array}$ & $\begin{array}{r}9,2 \\
13,7 \\
-0,9\end{array}$ & $\begin{array}{r}14,8 \\
13,0 \\
2,7\end{array}$ & $\begin{array}{l}1,0 \\
6,4 \\
3,0\end{array}$ \\
\hline $\begin{array}{l}\text { Exportaciones de bienes no tradicionales } \\
\text { (porcentaje de las exportaciones de bienes) }\end{array}$ & $\begin{array}{l}\text { Costa Rica } \\
\text { El Salvador } \\
\text { Honduras }\end{array}$ & $\begin{array}{l}50,5 \\
48,4 \\
36,3\end{array}$ & $\begin{array}{l}67,9 \\
34,1 \\
42,7\end{array}$ & $\begin{array}{l}79,5 \\
34,8 \\
44,0\end{array}$ \\
\hline $\begin{array}{l}\text { Exportaciones de la industria maquiladora } \\
\text { (porcentaje de las exportaciones de bienes) }\end{array}$ & $\begin{array}{l}\text { Costa Rica } \\
\text { El Salvador } \\
\text { Honduras }\end{array}$ & $\begin{array}{r}13,6 \\
17,5 \\
4,8\end{array}$ & $\begin{array}{r}9,0 \\
45,8 \\
20,0\end{array}$ & $\begin{array}{r}6,5 \\
57,8 \\
31,4\end{array}$ \\
\hline $\begin{array}{l}\text { Balanza comercial de bienes y servicios } \\
\text { (porcentaje del PIB) }\end{array}$ & $\begin{array}{l}\text { Costa Rica } \\
\text { El Salvador } \\
\text { Honduras }\end{array}$ & $\begin{array}{r}-5,4 \\
-14,5 \\
-7,5\end{array}$ & $\begin{array}{r}-1,5 \\
-12,9 \\
-7,7\end{array}$ & $\begin{array}{r}-1,8 \\
-15,3 \\
-15,9\end{array}$ \\
\hline PIB (tasa de crecimiento anual) & $\begin{array}{l}\text { Costa Rica } \\
\text { El Salvador } \\
\text { Honduras }\end{array}$ & $\begin{array}{l}5,4 \\
5,9 \\
2,8\end{array}$ & $\begin{array}{l}5,4 \\
3,9 \\
2,7\end{array}$ & $\begin{array}{l}3,0 \\
2,1 \\
3,6\end{array}$ \\
\hline $\begin{array}{l}\text { Importaciones de bienes y servicios } \\
\text { (tasa de crecimiento anual) }\end{array}$ & $\begin{array}{l}\text { Costa Rica } \\
\text { El Salvador } \\
\text { Honduras }\end{array}$ & $\begin{array}{r}9,9 \\
20,1 \\
3,8\end{array}$ & $\begin{array}{l}9,2 \\
8,8 \\
3,4\end{array}$ & $\begin{array}{l}2,2 \\
6,2 \\
2,8\end{array}$ \\
\hline $\begin{array}{l}\text { Importaciones de bienes de consumo } \\
\text { (porcentaje de las importaciones de bienes) }\end{array}$ & $\begin{array}{l}\text { Costa Rica } \\
\text { El Salvador } \\
\text { Honduras }\end{array}$ & $\begin{array}{l}21,6 \\
26,0 \\
21,4\end{array}$ & $\begin{array}{l}20,6 \\
24,2 \\
24,9\end{array}$ & $\begin{array}{l}18,7 \\
26,0 \\
29,6\end{array}$ \\
\hline $\begin{array}{l}\text { Importaciones de materias primas y bienes de capital } \\
\text { (porcentaje de las importaciones de bienes) }\end{array}$ & $\begin{array}{l}\text { Costa Rica } \\
\text { El Salvador } \\
\text { Honduras }\end{array}$ & $\begin{array}{l}78,0 \\
66,3 \\
76,8\end{array}$ & $\begin{array}{l}79,4 \\
56,5 \\
71,9\end{array}$ & $\begin{array}{l}81,3 \\
50,2 \\
67,9\end{array}$ \\
\hline $\begin{array}{l}\text { Importaciones de otros bienes } \\
\text { (porcentaje de las importaciones de bienes) }^{\mathrm{a}}\end{array}$ & $\begin{array}{l}\text { Costa Rica } \\
\text { El Salvador } \\
\text { Honduras }\end{array}$ & $\begin{array}{l}0,5 \\
7,7 \\
1,8\end{array}$ & $\begin{array}{r}0,1 \\
19,3 \\
3,2\end{array}$ & $\begin{array}{r}0,0 \\
23,8 \\
2,5\end{array}$ \\
\hline $\begin{array}{l}\text { Remesas netas de los trabajadores migrantes } \\
\text { (porcentaje de la balanza comercial de bienes y servicios) }\end{array}$ & $\begin{array}{l}\text { Costa Rica } \\
\text { El Salvador } \\
\text { Honduras }\end{array}$ & $\begin{array}{r}-^{\mathrm{b}} \\
70,9 \\
58,0\end{array}$ & $\begin{array}{l}13,8 \\
84,8 \\
62,0\end{array}$ & $\begin{array}{l}16,0 \\
88,7 \\
62,5\end{array}$ \\
\hline
\end{tabular}

Fuente: estimaciones sobre la base de datos de la Comisión Económica para América Latina y el Caribe (CEPAL), con excepción de los relativos a las remesas y al PIB, que corresponden a Banco Mundial, World Development Indicators [base de datos en línea] http://devdata.worldbank. org/dataonline/.

a Los "otros bienes" son, básicamente, importaciones para la industria maquiladora.

b El monto de remesas de los trabajadores migrantes fue demasiado reducido como para registrarlo separadamente en la balanza de pagos. 
no han sido particularmente altas. Como fuente de divisas, El Salvador y Honduras han dependido en mayor medida de las remesas de los trabajadores migrantes, sobre todo de los Estados Unidos, que desde 1995 han representado en promedio más del $62 \%$ y el $80 \%$ de la balanza comercial de bienes y servicios, respectivamente (véase el cuadro 1). Si bien el aumento de las exportaciones permitió la reducción del déficit comercial de Costa Rica pese al incremento de las importaciones, no ocurrió lo mismo en los otros dos países.

En los años noventa, el crecimiento económico fue del 5,4\% y del 4,9\% anual en Costa Rica y El Salvador, respectivamente, y apenas inferior al $3 \%$ en Honduras (véase el cuadro 1). En los primeros dos países se registró una marcada desaceleración económica en 2000-2003, cuando los precios mundiales de algunos de sus principales productos de exportación descendieron marcadamente, mientras que la modesta tasa de crecimiento de Honduras se mantuvo. ${ }^{1}$ El extraordinario desempeño comercial y el crecimiento de más del $4 \%$ del sector agrícola en la

\footnotetext{
${ }^{1}$ Aunque el período analizado es 1990-2003, vale la pena mencionar que la economía costarricense se recuperó en 2004-2005, al registrar un crecimiento levemente superior al 4\%. El Salvador también continuó
}

década de 1990 indican que los sectores de exportación que gozan de ventajas comparativas han sido fuente de crecimiento económico en Costa Rica (Sánchez, 2004). No obstante, el crecimiento de este país ha sido bastante equilibrado, pues los sectores industriales orientados a la exportación y los servicios relacionados con el comercio también se expandieron en forma satisfactoria (Sánchez y Sauma, 2006). Paradójicamente, pese a las reformas de la política comercial, la producción de bienes no comerciables ha desempeñado un papel más importante en el crecimiento de El Salvador y Honduras (Acevedo, 2004; Cuesta y Sánchez, 2004). Los sectores con ventajas comparativas de estos países no recibieron el impulso que se esperaba de las reformas y, por ejemplo, el crecimiento agrícola ha sido escaso, sobre todo en los años noventa (Sánchez, 2005).

La incidencia de la pobreza no es tan marcada en Costa Rica como en El Salvador y Honduras, e incluso la pobreza rural en este país es menor que la pobreza urbana en los otros dos (véase el cuadro 2). En la década de 1990, la evolución del empleo y de los salarios reales

creciendo en el mismo período, pero solo poco más del $2 \%$ al año. El crecimiento económico de Honduras fue similar al de Costa Rica.

CUADRO 2

$$
\text { Costa Rica, El Salvador y Honduras: incidencia de la pobreza y nivel y distribución }
$$
de los ingresos reales, años seleccionados del período 1990-2004

\begin{tabular}{|c|c|c|c|c|c|c|c|}
\hline \multirow[t]{2}{*}{ País } & \multirow[t]{2}{*}{ Año } & \multicolumn{2}{|c|}{$\begin{array}{l}\text { Salario real por trabajador } \\
\text { (mensual, en dólares) }\end{array}$} & \multirow[t]{2}{*}{$\begin{array}{l}\text { Coeficiente de Gini del } \\
\text { ingreso per cápita }\end{array}$} & \multicolumn{3}{|c|}{$\begin{array}{c}\text { Incidencia de la pobreza } \\
\text { (porcentaje de la población } \\
\text { por debajo de la línea de pobreza) }\end{array}$} \\
\hline & & Urbano & Rural & & Urbana & Rural & Nacional \\
\hline \multirow{5}{*}{ Costa Rica } & 1990 & 306 & 207 & 0,44 & 24,8 & 27,3 & 26,2 \\
\hline & 1997 & 450 & 327 & 0,45 & 19,3 & 24,8 & 22,5 \\
\hline & 1999 & 510 & 337 & 0,47 & 18,1 & 22,3 & 20,3 \\
\hline & 2002 & 521 & 355 & 0,49 & 17,5 & 24,3 & 20,3 \\
\hline & 2004 & 483 & 341 & 0,48 & 18,7 & 23,1 & 20,5 \\
\hline \multirow{5}{*}{ El Salvador } & 1995 & 197 & 86 & 0,51 & 45,8 & 64,4 & 54,2 \\
\hline & 1997 & 252 & 103 & 0,51 & 44,4 & 69,2 & 55,5 \\
\hline & 1999 & 281 & 147 & 0,52 & 38,7 & 65,1 & 49,8 \\
\hline & 2001 & 272 & 108 & 0,53 & 39,4 & 62,4 & 48,9 \\
\hline & 2004 & 259 & 133 & 0,49 & 41,2 & 56,8 & 47,5 \\
\hline \multirow{5}{*}{ Honduras } & 1990 & 148 & 55 & 0,62 & 69,8 & 88,0 & 80,5 \\
\hline & 1997 & 114 & 60 & 0,56 & 72,6 & 84,2 & 79,1 \\
\hline & 1999 & 157 & 87 & 0,56 & 71,7 & 86,3 & 79,7 \\
\hline & 2002 & 192 & 72 & 0,59 & 66,7 & 86,1 & 77,3 \\
\hline & 2003 & 186 & 60 & 0,59 & 62,7 & 84,8 & 74,8 \\
\hline
\end{tabular}

Fuente: Comisión Económica para América Latina y el Caribe (CEPAL), Panorama social de América Latina 2002-2003, LC/G.2209-P, Santiago de Chile, Publicación de las Naciones Unidas, No de venta: S.03.II.G.185, y Panorama social de América Latina 2006, LC/G.2326-P, Santiago de Chile, Publicación de las Naciones Unidas, $\mathrm{N}^{\mathrm{o}}$ de venta: S.06.II.G.133. 
ayudó a reducir la pobreza en Costa Rica y El Salvador (véanse los cuadros 1 y 2). En el primero, esta tendencia no se mantuvo en el nuevo milenio: la economía perdió dinamismo y aumentó la desigualdad de la distribución del ingreso medida según el coeficiente de Gini (véase el cuadro 2). ${ }^{2}$ La pobreza continuó disminuyendo en El Salvador no obstante la desaceleración económica, pues a pesar de que los salarios reales en general se redujeron la distribución del ingreso mejoró gracias a las remesas que ingresaron al país y en particular a las zonas rurales. Sin embargo, debido a que las tendencias de los salarios reales y la desigualdad del ingreso no favorecieron a la población urbana, el número de pobres urbanos aumentó. En el caso de Honduras, el empleo, el salario real y la distribución del ingreso evolucionaron satisfactoriamente en los años noventa, pero la reducción de la pobreza registrada en esa década fue modesta. Las tendencias del mercado laboral se volvieron menos propicias para los trabajadores hondureños a comienzos del nuevo milenio, cuando la distribución del ingreso también empeoró. Si bien la entrada de remesas al país favoreció a los más pobres, la distribución del ingreso se menoscabó pues ellas fluyeron sobre todo a las áreas urbanas y el salario real de los trabajadores rurales registró una caída mayor. Solo en Honduras la distribución del ingreso fue más equitativa en 2003 que en 1990, pero no hay pruebas claras de que esto haya obedecido a la reforma de la política comercial del país.

\section{III}

\section{Aspectos analíticos y metodológicos}

En Centroamérica, la reforma de la política comercial apuntó a aumentar los precios relativos o la rentabilidad de los bienes y servicios exportables, con miras a promover el crecimiento basado en las exportaciones. Las políticas de fomento pertinentes se orientan directamente a este resultado. Por otra parte, las reducciones arancelarias deberían disminuir el costo de los insumos importados utilizados en la producción de exportaciones o, en otras palabras, reducir el precio de los bienes y servicios importados con respecto a los exportables. Si la liberalización interna condujera a una reducción de los precios internos de los bienes y servicios no exportables, los precios relativos de los bienes y servicios exportables e importables (es decir, comerciables) también amentarían.

Como puede concluirse a partir del modelo de Heckscher-Ohlin-Samuelson de la teoría comercial tradicional y sus ampliaciones (Salvatore, 1995; Evans, 1989; Wood, 1994) o del modelo de economía dependiente que surge de los estudios sobre las pequeñas economías en desarrollo abiertas (Cox-Edwards y Edwards, 1994; Edwards, 1988), este tipo de ajuste de los precios relativos afectaría en última instancia la remuneración relativa de los trabajadores (esto es, la distribución del ingreso). Aunque

\footnotetext{
${ }^{2}$ El nivel de empleo en Costa Rica aumentó considerablemente hacia el nuevo milenio, incluso cuando la economía se desaceleraba (véase el cuadro 1). No obstante, esto se debió al aumento del empleo informal
} en el mercado laboral. estas teorías no se formularon para explicar los efectos de la política comercial en la pobreza, en los últimos años se han realizado trabajos empíricos sobre el tema. ${ }^{3}$ En las teorías mencionadas se tiende a pasar por alto los efectos que otros factores internos y externos, además de la política comercial, pueden tener en los precios relativos. Las alteraciones de los precios mundiales y los ajustes del tipo de cambio nominal, por ejemplo, también afectan los precios de los bienes y servicios comerciables. Asimismo, la afluencia de capital y de remesas de los trabajadores migrantes podrían afectar los precios relativos, entre otros factores, mediante el tipo de cambio.

Cualquier variación de los precios relativos, ya sea debido a las políticas macroeconómicas o a una perturbación externa, afectará los precios al consumidor y por ende los mercados de bienes y servicios. Las fluctuaciones de los ingresos por concepto de ventas y de los costos de los insumos modificarán la rentabilidad relativa de los sectores y, en consecuencia, cambiarán las opciones de inversión de los productores. Es probable que el consumo privado también varíe, aunque los efectos finales dependerán de otros factores que afectan los ingresos de los hogares, entre ellos el mercado laboral, las transferencias gubernamentales y las remesas del exterior. El gobierno podrá ajustar el gasto para responder a las variaciones de los ingresos tributarios

\footnotetext{
${ }^{3}$ Véanse, por ejemplo, Ganuza y otros (2002 y 2004), Sánchez (2004 y 2005) y Vos y otros (2006), entre otros estudios.
} 
o de los objetivos de las políticas sociales, provocando a su vez nuevas repercusiones en los mercados de bienes y servicios. Todos estos cambios se acompañarán de ajustes de la oferta y la demanda en los mercados de factores de producción. En último término, las consecuencias con respecto a la absorción interna también dependerán en parte de las repercusiones en los ingresos de los factores y podrían tener efectos de retroalimentación en el sistema de demanda mediante nuevos ajustes de los precios.

La demanda de factores de los productores variará a medida que cambie la rentabilidad relativa de los sectores. Esto a su vez afectará el nivel y probablemente la composición de la demanda de mano de obra, con repercusiones en el nivel y distribución de los ingresos laborales, sobre todo si la oferta de mano de obra responde en forma simultánea. Se supone que los efectos en el nivel y distribución de los ingresos de los hogares serán similares a los relativos a los ingresos laborales, pero este no será necesariamente el caso de los hogares que reciben transferencias gubernamentales y remesas o de los hogares de ingresos medios o altos que reciben ingresos no derivados del trabajo. El efecto final, sobre todo en el nivel y la distribución de los ingresos de los hogares, pero también en los precios al consumidor, determinará la capacidad de las unidades familiares de satisfacer las necesidades básicas de consumo y en consecuencia el nivel de pobreza.

A esta multiplicidad de mecanismos de transmisión se sumarán eventualmente ajustes macroeconómicos y es probable que su interacción también dependa de otros factores internos, tales como el cambio tecnológico, la dotación de capital humano y la productividad. Para captar esta amplia variedad de mecanismos de transmisión y de efectos recíprocos y sus repercusiones en los estratos más pobres se requiere un modelo de equilibrio general computable.

En este trabajo se utilizó un modelo de equilibrio general computable estático para cada uno de los tres países estudiados a fin de generar simulaciones cuyos resultados, unidos a las tendencias observadas, contribuyeron a fundamentar las aseveraciones de este documento. Este modelo tiene casi todas las características del conocido modelo de equilibrio general computable desarrollado en el Instituto Internacional de Investigaciones sobre Políticas Alimentarias, que se explica ampliamente en Löfgren y otros (2002). ${ }^{4}$ Pertenece a la familia de

\footnotetext{
${ }^{4}$ Como se detalla en Sánchez (2005), los cambios introducidos con respecto al modelo que figura en Löfgren y otros (2002) son pocos y de escasa importancia.
}

modelos de equilibrio general computable neoclásicos, con ciertas características estructuralistas, creados para el análisis de la política comercial y cuyos fundamentos teóricos se detallan en Dervis y otros (1982) y Robinson (1989). Se trata de un modelo apropiado para realizar análisis de las políticas y de las perturbaciones externas y medir los efectos de ambas en los precios relativos y, en consecuencia, en la asignación de los recursos y la distribución del ingreso. Una característica particular del modelo es que incluye funciones de sustitución imperfectas en virtud de las cuales, dado un cambio en los precios relativos a valores de elasticidad determinados: i) el productor sustituye bienes intermedios por factores de producción y viceversa, ii) el productor sustituye unos factores de producción por otros, iii) el productor sustituye el mercado interno por el externo y viceversa al distribuir la producción, y iv) el consumidor sustituye el consumo de productos nacionales por el consumo de productos importados y viceversa.

La base de datos para la calibración del año base del modelo de equilibrio general computable de cada país proviene de una matriz de contabilidad social y datos relativos a las elasticidades y la dotación de factores. La matriz de contabilidad social proporciona la coherencia contable y las dimensiones del modelo - es decir, el número de actividades de producción, bienes y servicios, factores e instituciones- Las elasticidades, por otra parte, definen el grado de sustitución como parte de los problemas de optimización que enfrentan tanto el productor como el consumidor, en respuesta a una variación de los precios relativos.

Los datos correspondientes a Costa Rica fueron recopilados originalmente por Sánchez (2004) para realizar un análisis del modo en que la reforma de la política comercial incidió en la pobreza en dicho país. En El Salvador y Honduras también se realizaron estudios similares del nexo entre comercio y pobreza, como informan Ganuza y otros (2004). Las matrices de contabilidad social y demás datos necesarios para este trabajo se tomaron de esos estudios. Las matrices de contabilidad social de Costa Rica y Honduras corresponden al año 1997, mientras que la de El Salvador corresponde a 1999, siendo estos los respectivos años base del modelo de equilibrio general computable de cada país.

Las matrices de contabilidad social son muy detalladas desde el punto de vista sectorial —es decir, abarcan un gran número de actividades y bienes y servicios- y las variaciones entre los países reflejan sus diferentes estructuras de producción. Los principales productos de exportación están debidamente identificados, mientras 
que los sectores que desempeñan un papel muy poco significativo en la economía figuran en forma agregada. Las demás cuentas de las matrices de contabilidad social —relativas a factores e instituciones - se presentan en forma más estandarizada. En particular, la mano de obra se clasifica de acuerdo con el nivel de calificación y la categoría ocupacional. Todas las elasticidades se definen a nivel sectorial —es decir, tanto respecto de las actividades como de los bienes y servicios- de modo de reflejar el comportamiento de productores y consumidores específicos según el sector. Aunque los datos incorporados en el modelo necesariamente difieren de un país a otro en cuanto a la desagregación y los valores proporcionados, los resultados de las simulaciones son comparables debido a que las funciones del modelo son las mismas para los tres casos.

Los modelos de equilibrio general computable basados en matrices de contabilidad social tradicionales brindan resultados relativos a la desigualdad de ingresos entre grupos en diferentes conjuntos de hogares, pero no producen resultados con respecto a la desigualdad dentro de un mismo grupo, a pesar de que esto también es importante para explicar la desigualdad total de los ingresos y la pobreza. Para superar esta limitación, el modelo de equilibrio general computable de cada país se combinó con una metodología de microsimulación desarrollada originalmente por Almeida dos Reis y Paes de Barros (1991) para analizar la desigualdad de ingresos. Este método se perfeccionó para analizar la desigualdad de los ingresos per cápita de los hogares y la pobreza en el marco de un análisis de equilibrio general, como se explica en Ganuza y otros (2002).

La metodología de microsimulación permite, básicamente, aislar las variaciones en la desigualdad y la pobreza que obedecen a ajustes del mercado laboral. El modelo de equilibro general computable proporciona una estructura del mercado de trabajo en el año base idéntica a la que se calcularía a partir de los datos de las encuestas de hogares utilizados para calibrar el modelo y calcular las medidas de desigualdad y pobreza del año base. ${ }^{5}$ La simulación de una política o de una

\footnotetext{
${ }^{5}$ La estructura del mercado laboral, ya sea del año base o una simulación, se determina mediante las tasas de participación económica
}

perturbación externa de este tipo puede utilizarse para generar una estructura de mercado laboral contraria a la realidad, que luego se impone en forma secuencial —de arriba hacia abajo- a los datos de la encuesta de hogares para generar números aleatorios a partir de una distribución normal. Esto tiene dos objetivos: en primer lugar, determinar cuántas personas en edad de trabajar cambian de categoría o se mueven de un segmento del mercado laboral a otro como resultado de la situación simulada y, en segundo lugar, asignar ingresos laborales a individuos que se incorporaron recientemente al empleo, utilizando el ingreso medio del decil de distribución al que pertenecían los trabajadores de iguales características socioeconómicas que ya estaban empleados. Se supone que, en promedio, los efectos de los cambios aleatorios reflejan correctamente las repercusiones de los cambios reales en el mercado laboral. Debido a que la oferta de mano de obra y las decisiones en materia de ocupación se abordan como procesos en gran medida aleatorios, las microsimulaciones se repiten varias veces con el método de Monte Carlo para permitir la construcción de intervalos de confianza del $95 \%$ para los índices de desigualdad y pobreza. ${ }^{6}$ Estos últimos se comparan con los índices de desigualdad y pobreza del año base para poder formular conclusiones. Al determinar los efectos en la distribución del ingreso se tiene en cuenta a todas las personas que figuran en la base de datos de la encuesta de hogares.

y desempleo, la estructura del empleo según la definición por sector de actividad económica y categoría ocupacional, la estructura de las remuneraciones definida por actividad económica, la remuneración media en la economía y la composición de la mano de obra empleada por nivel de calificación. Véanse más detalles en Ganuza y otros (2002).

${ }^{6}$ Se usaron las líneas de pobreza e indigencia calculadas de manera endógena, sobre la base de los sistemas de precios y gasto del modelo de equilibro general computable, aplicando el procedimiento detallado en Sánchez (2005). Estas líneas se utilizaron para calcular índices de pobreza después de cada microsimulación, considerando que por lo general las políticas y las perturbaciones externas afectan los precios de los bienes y servicios de consumo básico. 


\section{IV}

\section{Análisis de los resultados de la simulación}

Una vez calibrado y resuelto en forma viable con datos relativos a cada uno de los tres países, utilizando el sistema general de modelado algebraico (GAMS, por sus siglas en inglés), el modelo de equilibrio general computable se usó para realizar varias simulaciones de políticas y perturbaciones externas. Los resultados de estas se examinan en esta sección y se detallan en el cuadro 3 como variaciones porcentuales respecto del valor del año base. La mayoría de las simulaciones se realizó de acuerdo con un conjunto de reglas de cierre establecidas inicialmente para asegurar el equilibrio en los diferentes mercados abarcados por el modelo. En el mercado de factores, por ejemplo, el desempleo permite alcanzar un "equilibrio" respecto del capital, la mano de obra asalariada no calificada y la mano de obra independiente (calificada y no calificada). El nivel de desempleo de la mano de obra asalariada calificada se mantiene fijo y el salario equilibra el mercado de este factor. Una vez más, la diferencia entre los ingresos ordinarios y los gastos corrientes del gobierno corresponde al ahorro del gobierno. La balanza de la cuenta corriente con el resto del mundo se compensa mediante el ahorro externo y el tipo de cambio se mantiene fijo, de acuerdo con los sistemas cambiarios predominantes en los tres países en el año base. Solo se modificó esta regla de cierre relativa al sector externo para realizar algunas simulaciones. El ahorro se equiparó a la inversión utilizando una regla de cierre "balanceada" mediante la cual los efectos en la absorción se distribuyen proporcionalmente entre sus componentes. La inversión y el consumo público representaron una porción fija de la absorción nominal del año base y, dada esta especificación, también se fijó de forma implícita la parte residual correspondiente al consumo de los hogares. Las tasas de ahorro de los hogares y empresas se ajustaron por número igual de puntos porcentuales de modo que los ahorros globales se equipararan a la inversión total. ${ }^{7}$

\footnotetext{
${ }^{7}$ Esta regla de cierre "neutral" disminuye el riesgo de que los principales agregados macroeconómicos presenten fluctuaciones irregulares cuando las simulaciones producen cambios considerables de la balanza comercial o del gobierno.
}

\section{Reformas de la política comercial}

La reforma de la política comercial simulada consistió en una reducción del $50 \%$ de los aranceles que gravan a todos los bienes y servicios importados (liberalización de las importaciones) y una disminución del 50\% de los impuestos que gravan a todos los productos exportados (promoción de las exportaciones). ${ }^{8}$ La magnitud de los cambios fue deliberadamente alta para simular una reforma profunda de la política comercial. ${ }^{9}$ Estas intervenciones se aplicaron a todos los sectores de bienes comerciables (importables y exportables) de manera uniforme para evitar la mayor protección de algunos respecto de otros. Debido a que la institución "resto del mundo" del modelo no distingue a los diferentes socios comerciales, las políticas de liberalización de las importaciones y promoción de las exportaciones simuladas tampoco discriminan entre ellos. Como lo indican estas consideraciones, el objetivo de las simulaciones no era simular un acuerdo comercial real, sino producir resultados estáticos comparables.

Los resultados de esta simulación de reforma de la política comercial coinciden bastante con lo que ocurrió realmente en Costa Rica. Cuando se simula la liberalización de las importaciones, al comienzo aumenta la demanda final interna, pero luego los recursos se desplazan rápidamente de la producción para el mercado interno hacia los sectores de exportación, en respuesta a la medida de promoción de las exportaciones. La reducción de la oferta para el mercado interno se traduce en una menor absorción interna. Sin embargo, la producción no comerciable no se contrae, sino que aumenta más o menos a la par de la producción comerciable debido a

\footnotetext{
${ }^{8}$ Debido a que en la matriz de contabilidad social de El Salvador no se registraron tasas impositivas sobre las exportaciones, la política de promoción de las exportaciones de ese país se simuló mediante un aumento del 50\% del subsidio implícito en el precio de las exportaciones agrícolas no tradicionales, es decir, todas las exportaciones agrícolas con excepción del café, el algodón, la caña de azúcar y los cereales básicos.

${ }^{9}$ Pese a la magnitud relativamente elevada del cambio simulado en los instrumentos de política comercial, los modelos de los tres países permanecieron estables después de su aplicación y se resolvieron fácilmente.
} 


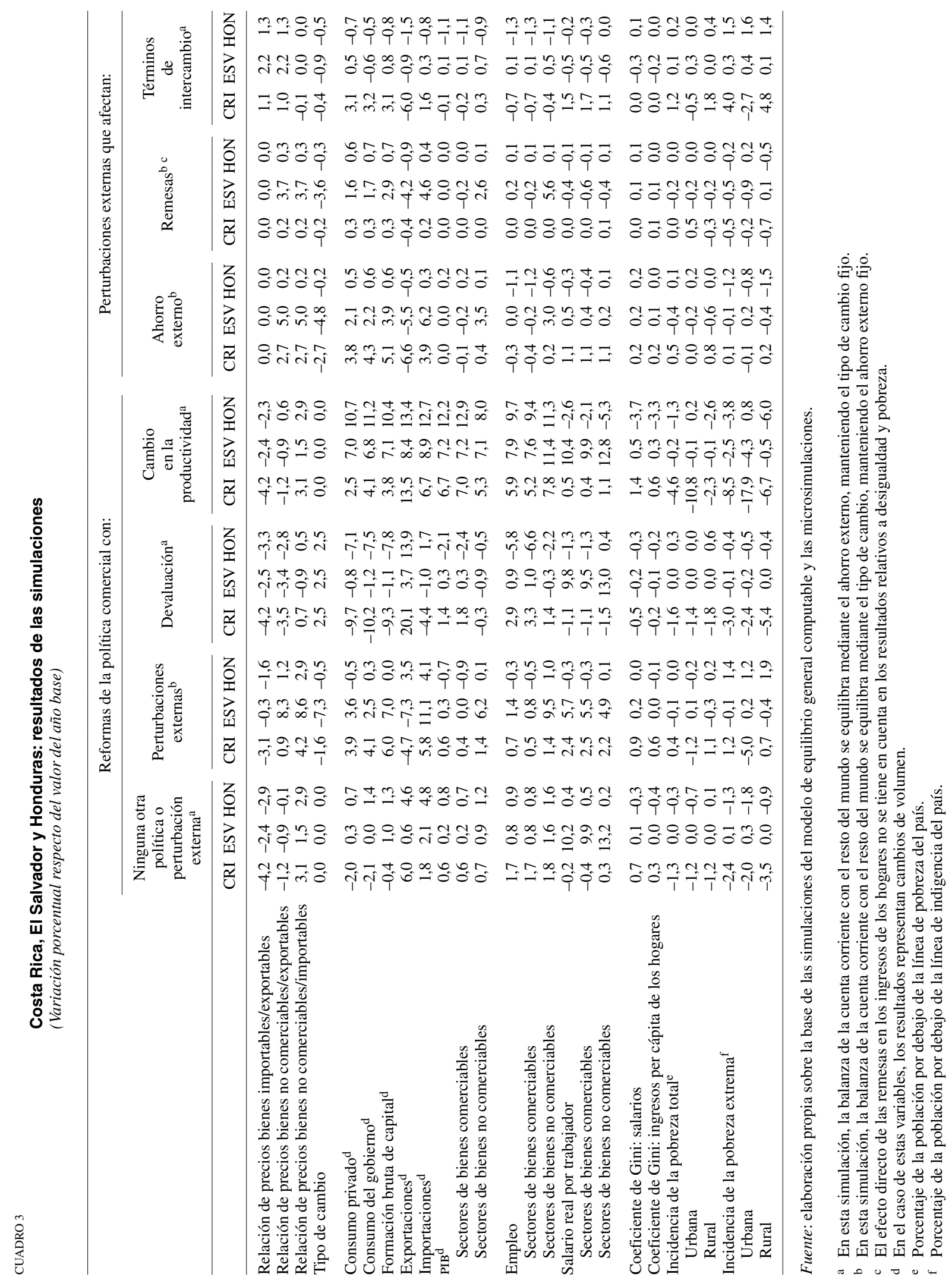


fuertes vínculos con el sector exportador. ${ }^{10}$ En forma análoga, la medida de promoción de las exportaciones simulada reduce la producción para el mercado interno en El Salvador y Honduras, pero, a diferencia de Costa Rica, en estos países no compensa plenamente los beneficios a que da lugar la baja de los aranceles. Estos resultados concuerdan con el hecho paradójico antes mencionado de que en El Salvador y Honduras la actividad económica en los sectores de bienes no comerciables ha sido un factor clave para el crecimiento general durante las reformas de la política comercial. La producción aumenta un $0,6 \%$, un $0,2 \%$ y un $0,8 \%$ en Costa Rica, El Salvador y Honduras, respectivamente, pero -una vez más de acuerdo con los hechos reales- solo en Costa Rica ella aumenta de manera más balanceada en los sectores de bienes comerciables y no comerciables y el crecimiento de las exportaciones es suficiente para reducir el déficit comercial. En los otros dos países, la producción aumenta más marcadamente en los sectores de bienes no comerciables y las importaciones crecen más que las exportaciones.

El empleo aumenta un poco más rápido que la producción, en especial en Costa Rica, sobre todo porque no se modela ningún vínculo endógeno entre la política comercial y la productividad. Nuevamente, la variación en el empleo se distribuye en forma más uniforme entre los sectores de bienes comerciables y no comerciables en Costa Rica, en parte debido a que la medida de promoción de las exportaciones también estimula el empleo agrícola. Una mayor proporción de la mano de obra recién contratada en El Salvador y Honduras se emplea en los sectores de bienes no comerciables, debido a que predomina el efecto de la reducción arancelaria. Al parecer esto determina en ambos países el ajuste final de los salarios, los cuales superan los valores del año base, sobre todo en El Salvador. El efecto de la medida de promoción de las exportaciones en los salarios compensa parcialmente el de la liberalización de las importaciones en Honduras y totalmente en Costa Rica, donde en general se registra una pequeña baja. En los tres países, la reducción simulada de los aranceles sobre las importaciones amplía de modo inequívoco las brechas salariales entre los trabajadores asalariados e independientes y entre los trabajadores calificados y no calificados (esto no se aprecia en el cuadro 3). La distribución de los ingresos laborales medida

\footnotetext{
10 Sánchez (2007) sostiene que en Costa Rica la diversificación de las exportaciones abrió el camino a los cambios en la estructura de producción que, en última instancia, derivaron en la creación de vínculos de producción entre sectores.
}

según el coeficiente de Gini empeora en Costa Rica y El Salvador. En Honduras, por el contrario, el ajuste del empleo deriva en una reducción de la desigualdad de los ingresos laborales. La medida de promoción de las exportaciones incrementa la desigualdad en Costa Rica debido a su impacto en la estructura de empleo según el tipo de trabajador. El efecto contrario se observa en El Salvador, donde la diferencia entre los ingresos de los trabajadores calificados y no calificados se reduce cuando se promueven las exportaciones. En Honduras no se observan cambios de importancia en este sentido. Consideradas en conjunto, las reformas de la política comercial simuladas deterioran levemente la distribución de los salarios en Costa Rica y producen una pequeña mejora en Honduras, mientras que en El Salvador se observan pocos cambios. Estos efectos distributivos se reproducen ampliamente a nivel de los ingresos per cápita de los hogares.

La combinación del incremento de los ingresos laborales de los hogares y la pequeña baja de los costos del consumo básico conduce a una reducción de la incidencia de la pobreza, sobre todo en Costa Rica, donde podría haber sido aún mayor de no haberse deteriorado la distribución del ingreso. La mejora en la distribución del ingreso también contribuye a reducir la pobreza en Honduras, pero la incidencia de ella se mantiene básicamente inalterada en El Salvador, donde un leve aumento de la desigualdad salarial más bien parece influir en forma desproporcionada en las personas extremadamente pobres de las zonas urbanas. La incidencia de la pobreza disminuye en mayor medida en Costa Rica, pues la situación de quienes viven en condiciones de extrema pobreza en las áreas rurales es mucho mejor que en los otros dos países.

Como ya se mencionó, en Costa Rica la desigualdad de ingresos aumentó en el período 1997-2002, mientras que, en general, la incidencia de la pobreza disminuyó, sobre todo en las zonas rurales (véase el cuadro 2). Estos hechos concuerdan con los resultados de la simulación. ${ }^{11}$ En Honduras se llevaron a cabo reformas de la política comercial similares a las de Costa Rica en el mismo período, solo que con menor rapidez, y se observó una reducción general de la incidencia de la pobreza, aunque la desigualdad de ingresos empeoró entre 1999 y 2002. De acuerdo con los resultados de la simulación, las reformas de la política comercial

\footnotetext{
11 Vale la pena recordar en este punto que el año base del modelo de equilibrio general computable es 1997 en el caso de Costa Rica y Honduras y 1999 en el de El Salvador.
} 
deberían haber ayudado a reducir la pobreza extrema en Honduras mediante el incremento del empleo y la mejora de los salarios. No obstante, el deterioro de la distribución del ingreso debe haberse contrarrestado plenamente por el efecto distributivo de las corrientes de remesas de los trabajadores migrantes. Las reformas de la política comercial no han sido los principales factores determinantes de la desigualdad de ingresos y la pobreza en El Salvador, donde las remesas han tenido mayor importancia. En resumen, la combinación de los resultados de la simulación y los hechos reales sugiere que es en Costa Rica donde las reformas de la política comercial han influido más claramente en la evolución de la pobreza y la desigualdad de ingresos. A continuación se procurará explicar el motivo.

\section{Reforma de la política comercial, tipo de cambio y competitividad de las exportaciones}

Como se señaló anteriormente, el objetivo de las reformas de la política comercial era incrementar la rentabilidad relativa de las exportaciones. No obstante, diversos factores externos contribuyeron a que se elevara el tipo de cambio real, reduciendo de ese modo dicha rentabilidad. Entre ellos figuran la cuantiosa entrada de remesas de los trabajadores migrantes (véase el cuadro 1), pero también otras corrientes de capital privado e inversión extranjera directa, que comenzaron a llegar en volúmenes considerables a principios de los años noventa, cuando se desmantelaron los controles de capital, se alcanzó una mayor estabilidad económica y política y se establecieron diversos incentivos para los inversionistas extranjeros (véase el cuadro 4). Además, las frecuentes bajas de los precios mundiales de bienes y servicios de exportación clave (café y azúcar, entre otros) y el alza desmesurada de los del petróleo empeoraron los términos del intercambio de estos países a comienzos del nuevo milenio, ejerciendo de ese modo más presión sobre el tipo de cambio real (véase el cuadro 4). No hay grandes perspectivas de que esta tendencia se invierta en forma sostenida. Si bien es posible que se haya incrementado el valor de algunos de los bienes y servicios de exportación clave de los países centroamericanos, eventualmente volverá a bajar debido a la desaceleración de la economía mundial. En general, los precios del petróleo y de algunos alimentos básicos importados han continuado aumentando pese a la desaceleración de la economía global.

El modelo de equilibrio general computable también se utilizó para simular un aumento del $25 \%$ de las entradas de capital, un incremento del $25 \%$ de las remesas y una reducción del $5 \%$ del precio mundial de las principales exportaciones (es decir, una alteración de los términos de intercambio), ${ }^{12}$ los cuales se consideran perturbaciones externas en el análisis que se presenta en esta sección. El incremento de las entradas de capital

\footnotetext{
12 Para simular la perturbación de los términos de intercambio, se modificó el precio mundial de las exportaciones en los modelos computarizados de equilibrio general, de modo que los bienes y servicios representaran alrededor del $30 \%$ de las exportaciones de cada país ("productos agrícolas no tradicionales" en Costa Rica, "otros servicios" en El Salvador y "alimentos, bebidas y tabaco" en Honduras).
}

Costa Rica, El Salvador y Honduras: entradas brutas de capital privado e inversión extranjera directa y términos de intercambio netos, 1990-2003 (Promedio anual del período de referencia)

\begin{tabular}{|c|c|c|c|c|}
\hline Indicador & País & 1990-1994 & 1995-1999 & $2000-2003$ \\
\hline \multirow{3}{*}{ Entradas brutas de capital privado (porcentaje del PIB) } & Costa Rica & 5,3 & 8,7 & 9,2 \\
\hline & El Salvador & 1,3 & 6,2 & 15,2 \\
\hline & Honduras & 6,8 & 7,5 & 7,6 \\
\hline \multirow{3}{*}{ Inversión extranjera directa neta (porcentaje del PIB) } & Costa Rica & 2,7 & 3,6 & 3,1 \\
\hline & El Salvador & 1,3 & 2,5 & 3,5 \\
\hline & Honduras & 0,2 & 2,4 & 1,9 \\
\hline \multirow{3}{*}{ Términos de intercambio netos $(2000=100)$} & Costa Rica & 84,9 & 105,1 & 100,3 \\
\hline & El Salvador & 83,5 & 113,0 & 94,5 \\
\hline & Honduras & 83,4 & 103,3 & 95,1 \\
\hline
\end{tabular}

Fuente: Banco Mundial, World Development Indicators [base de datos en línea] http://devdata.worldbank.org/dataonline/. 
se simuló mediante cambios en el ahorro externo, manteniéndolo fijo y exógeno, mientras que la cuenta corriente con el resto del mundo se balanceó mediante el tipo de cambio de acuerdo con la alternativa al cierre del modelo original. Esta regla alternativa también se utilizó para simular el aumento de las remesas, puesto que también podrían influir de manera considerable en el tipo de cambio. El crecimiento de las remesas se simuló mediante el incremento de las transferencias del exterior a los hogares en el modelo de equilibrio general computable, pero el efecto en la distribución del ingreso y la pobreza se analizó en dos etapas. En la primera, el aumento del ingreso de los hogares como resultado del incremento de las remesas no se consideró para realizar las microsimulaciones. En otras palabras, el análisis inicial de la distribución del ingreso y la pobreza en la simulación de las remesas solo aborda el efecto "puro" en los precios relativos que provoca la entrada de ellas por medio del mercado laboral. El efecto "pleno" de las remesas en la distribución del ingreso y la pobreza se analizó en una segunda etapa, en la que se incluyó el incremento del ingreso de los hogares en las microsimulaciones.

Las tres perturbaciones externas simuladas derivaron en una marcada apreciación del tipo de cambio (véase el cuadro 3). Los recursos se reasignaron desde los sectores de bienes comerciables a los de no comerciables debido a los efectos en los precios relativos. Como consecuencia de ello, aumentó la absorción interna, pero la producción se incrementó apenas debido al deterioro de la balanza comercial y a las repercusiones adversas en la producción de bienes comerciables en comparación con la de bienes no comerciables. La alteración de los términos de intercambio en Honduras constituye la única excepción. ${ }^{13}$

El empleo se contrae en mayor medida en los sectores de bienes comerciables, en particular la agricultura, aunque algunas de las simulaciones también muestran una reducción del empleo en los sectores de bienes no comerciables en Costa Rica y Honduras. El aumento de las contrataciones en los sectores de bienes no comerciables en El Salvador compensa su disminución en los sectores de bienes comerciables, de modo

\footnotetext{
${ }^{13}$ En forma más atípica, en Honduras el deterioro de los términos del intercambio simulado reduce casi un 1\% la producción de bienes no comerciables. Esto se debe a que el aumento simulado del precio mundial de los alimentos, bebidas y tabaco desalienta la producción de estos bienes para el mercado interno y, en consecuencia, disminuye la demanda interna de bienes nacionales e importados.
}

que el empleo total aumenta ligeramente o se mantiene casi invariable. En las tres simulaciones, la caída de los precios internos provocada por la apreciación del tipo de cambio hace bajar los salarios, excepto en Costa Rica y en El Salvador cuando se simulan mayores entradas de capital. En estas situaciones, la mayor demanda de trabajadores calificados en los sectores de bienes no comerciables termina por elevar los salarios. El repunte de los sectores de bienes no comerciables se traduce en brechas salariales más amplias entre los trabajadores asalariados e independientes y entre los trabajadores calificados y no calificados, excepto en el caso de la perturbación de los términos de intercambio en El Salvador. Como resultado, la distribución del ingreso medida según el coeficiente de Gini empeora muy levemente. El efecto en la pobreza es más ambiguo. La incidencia total de la pobreza aumenta en general en Costa Rica debido al descenso de los ingresos laborales rurales, excepto cuando se incrementan las remesas, pues estas reducen el número de personas que viven en condiciones de extrema pobreza, sobre todo en las zonas rurales. El repunte de los sectores de bienes no comerciables reduce de modo inequívoco la extrema pobreza en las áreas urbanas de Costa Rica. En El Salvador, el aumento de las entradas de capital, incluidas las remesas, deriva en una modesta reducción de la pobreza total y extrema como consecuencia del efecto redistributivo de las variaciones que registra el mercado laboral en los sectores de bienes no comerciables. En Honduras también se observa una reducción de la extrema pobreza, sobre todo en las zonas rurales, pero ella se explica por la presión a la baja de los precios de los alimentos. El deterioro de los términos del intercambio perjudica en cierta medida la incidencia de la pobreza en El Salvador y Honduras debido a sus efectos en los ingresos de los hogares, que tienden a ser más graves para los más pobres.

Los resultados de las simulaciones indican que, en general, el incremento de las entradas de capital, incluidas las remesas, y los efectos desfavorables del deterioro de los términos del intercambio no explican en gran medida la desigualdad y la pobreza. No obstante, habría que examinar más detenidamente los efectos de las remesas, dado que, como ya se señaló, solo se ha analizado el efecto "parcial" a que da lugar el funcionamiento del mercado laboral. Cuando también se tienen en cuenta las transferencias a los hogares en las microsimulaciones, las repercusiones en la desigualdad de ingresos y la pobreza son mucho más evidentes en El Salvador y Honduras, donde las remesas representan parte considerable de la balanza comercial (véase el 
cuadro 1). Como lo indica el gráfico 2, la distribución del ingreso per cápita de los hogares mejora notablemente en El Salvador, donde la mayor parte de las remesas se destina a las zonas rurales, pero se deteriora en Honduras, donde favorecen principalmente a los hogares urbanos. El número de personas que vive en condiciones de moderada y extrema pobreza disminuyó de manera apreciable, pero este efecto es mucho más marcado en El Salvador debido a la mejora en la distribución del ingreso. El trabajo no incluye los resultados relativos a Costa Rica, porque son casi nulos debido a que el monto de las remesas fue inferior al de los otros dos países en el año base del modelo. ${ }^{14}$

${ }^{14}$ Aun hoy, el monto de las remesas continúa siendo muy inferior en Costa Rica. De acuerdo con los Indicadores del desarrollo mundial 2006 del Banco Mundial, las remesas netas de los trabajadores migrantes equivalieron al $19,1 \%$, al $93,8 \%$ y al $96,3 \%$ de la balanza comercial de bienes y servicios en Costa Rica, El Salvador y Honduras, respectivamente.

GRÁFICO 2

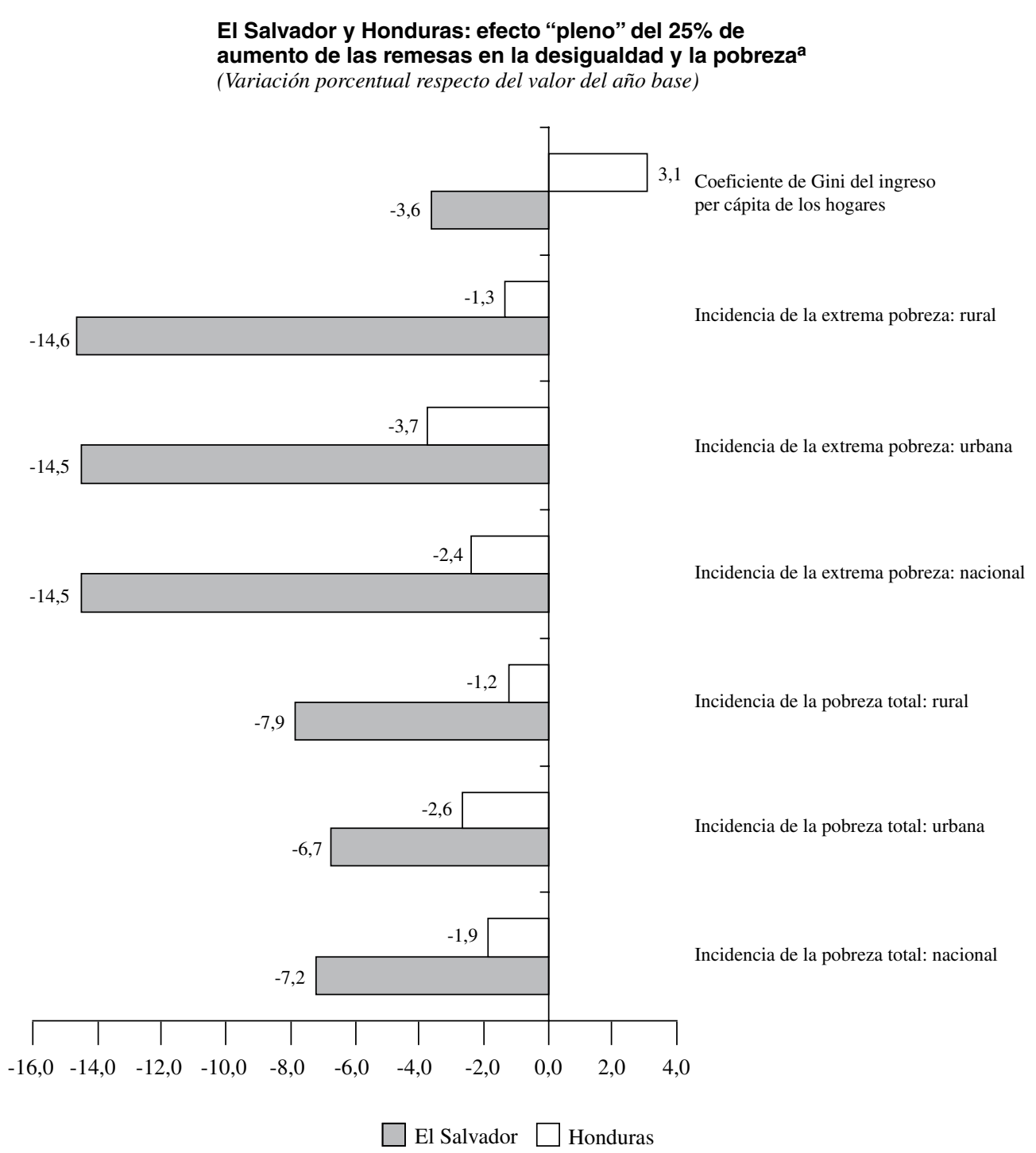

Fuente: elaboración propia sobre la base de las simulaciones del modelo de equilibrio general computable y las microsimulaciones.

a Las estimaciones incluyen los efectos directos de las remesas en el ingreso de los hogares en las microsimulaciones. 
Se comprobó que las remesas no afectan mayormente la producción por medio de los precios relativos y sus repercusiones en la distribución del ingreso y la pobreza se explican más que nada porque se transfieren en forma directa a los hogares. ${ }^{15}$ Este resultado puede indicar que El Salvador y Honduras carecen de capacidad para absorber las corrientes de remesas en forma productiva y que el sector exportador de esos países se ve seriamente afectado por la consiguiente apreciación del tipo de cambio. De mantenerse estas circunstancias en El Salvador y Honduras, donde las remesas continúan aumentando en forma sistemática, estos países podrían terminar por experimentar el fenómeno que Sánchez (2005) denomina "el mal de las remesas".

Las repercusiones de la apreciación del tipo de cambio son importantes para el éxito relativo de las reformas de la política comercial, como lo indican los resultados de una nueva simulación en la que se combinan estas reformas con las perturbaciones externas simuladas. ${ }^{16}$ La apreciación del tipo de cambio, provocada principalmente por dichas alteraciones, fomenta el consumo, la inversión y las exportaciones en comparación con el escenario en que las reformas de la política comercial no se acompañan de otras conmociones externas. Honduras constituye la excepción, pues la producción agrícola para el consumo interno resulta severamente afectada como consecuencia de la menor actividad económica en la fabricación de artículos de exportación, lo que se traduce en una menor producción. En este caso, el consumo de los hogares rurales disminuye, el consumo del gobierno se expande solo levemente y el efecto en la producción desalienta las importaciones, en comparación con la situación en que solo se prevén reformas de la política comercial. Las exportaciones, en particular agrícolas, se desincentivan en los tres países y aumenta el déficit comercial. No obstante, la producción no se contrae en forma marcada en Costa Rica o El Salvador debido a

\footnotetext{
${ }^{15}$ Esta conclusión sigue siendo válida incluso si se mantiene la regla de cierre inicial del modelo según la cual el tipo de cambio está fijo y la cuenta corriente con el resto del mundo se equilibra mediante el ahorro externo.

16 Para esta nueva simulación, se partió de la base de que el tipo de cambio era flexible (y el ahorro externo fijo), pese a que al inicio se había supuesto lo contrario, al simular únicamente las reformas de la política comercial. En una simulación experimental en que se utilizó un tipo de cambio flexible, y de la que no se informa en este documento, las reformas de la política comercial se tradujeron en una apreciación muy marginal del tipo de cambio y los efectos en la asignación de los recursos y la distribución del ingreso y la pobreza permanecieron básicamente iguales a los generados cuando se asumió que el tipo de cambio era fijo (y el ahorro externo flexible).
}

que los recursos retirados de los sectores de exportación se redistribuyen rápidamente en la producción de bienes no comerciables.

Las perturbaciones externas contrarrestan parcialmente los efectos positivos de las reformas de la política comercial en el mercado laboral en Costa Rica y El Salvador y en forma plena en Honduras. El empleo y los salarios disminuyen en Honduras, sobre todo en los sectores de bienes comerciables. El empleo total aumenta en Costa Rica en menor medida que en los casos en que no hay conmociones externas, pero los salarios terminan por aumentar debido a la mayor demanda de trabajadores calificados en los sectores no agrícolas. En cambio, en El Salvador se observan nuevas fuentes de empleo para los trabajadores de todos los tipos en los sectores de bienes no comerciables, pero la reducción de los precios internos provocada por la apreciación del tipo de cambio disminuye el salario medio en comparación con la situación en que no se prevén conmociones externas. Además, la apreciación del tipo de cambio también aumenta en cierta medida el efecto de las reducciones arancelarias en la distribución del ingreso en los tres países y en general anula la reducción de la pobreza registrada en Costa Rica y Honduras en ausencia de conmociones externas. Por el contrario, la pobreza disminuye ligeramente en El Salvador como resultado del repunte de los sectores de bienes no comerciables.

El tipo de cambio real se apreció realmente tanto en Honduras como en El Salvador (véase el gráfico 3) y, si se toman por ciertos los resultados de la simulación, esto debe haber contrarrestado los efectos previstos de las reformas de la política comercial. En El Salvador se optó por un sistema de tipo de cambio fijo en 1993 y se dolarizó la economía en 2001, período en que el tipo de cambio real se apreció en forma significativa. No es sorprendente, entonces, que de una economía agroexportadora El Salvador se haya transformado en una economía de servicios (Segovia, 1998). Los sectores de bienes no comerciables han impulsado el crecimiento económico en este país, sobre todo en los años noventa. En el caso de Honduras, las intervenciones periódicas en el mercado de divisas desde 1994 han sido insuficientes para impedir la apreciación del tipo de cambio real. El modesto desempeño económico del país se ha sostenido mediante aumentos transitorios de la inversión y el consumo públicos desde la década de 1990 (Cuesta y Sánchez, 2004). En Costa Rica, por el contrario, un sistema controlado de minidevaluaciones periódicas de la moneda local respecto del dólar ha permitido mantener un tipo de cambio relativamente estable y competitivo 
(véase el gráfico 3). ${ }^{17}$ De ese modo, solo la política cambiaria de Costa Rica ha demostrado ser coherente con los objetivos de las reformas de la política comercial, pues las pequeñas devaluaciones realizadas en el país han contribuido a aumentar la rentabilidad relativa de las exportaciones.

La devaluación intensifica los efectos de las reformas de la política comercial. La rentabilidad relativa de las exportaciones aumenta marcadamente cuando las reformas de la política comercial simuladas se combinan con una devaluación del 2,5\% del tipo de cambio (véase el cuadro 3). ${ }^{18}$ Las exportaciones aumentan en forma considerable a expensas de una menor inversión en los sectores de bienes no comerciables, pero solo en Costa Rica incrementan el PIB en forma sustancial, en comparación con el escenario en que solo se modifica la política comercial (véase el cuadro 3). El PIB disminuye en Honduras, no solo debido a que se contrae la producción de bienes no comerciable, sino también porque la devaluación aumenta los costos

\footnotetext{
${ }^{17}$ En enero de 2007, Costa Rica adoptó un nuevo sistema controlado con bandas de fluctuación máximas y mínimas.

${ }^{18}$ En esta simulación se aplicó la regla de cierre inicial en virtud de la cual el tipo de cambio se mantiene fijo y la cuenta corriente con el resto del mundo se equilibra mediante el ahorro externo.
}

de producción en un sector exportador improductivo y poco diversificado. Cuesta y Sánchez (2004) identifican otros mecanismos de transmisión mediante los cuales en Honduras la devaluación tiene efectos contractivos según un análisis de equilibrio general.

La devaluación simulada fortalece el efecto en el empleo de las reformas de la política comercial en Costa Rica y El Salvador, pues se emplea más trabajadores en los sectores de bienes comerciables, aunque a expensas de menos contrataciones en los sectores de bienes no comerciables. En Honduras el empleo disminuye en todos los sectores como resultado del efecto contractivo de la devaluación. Esta provoca el alza de los precios internos y en la mayoría de los casos deriva en la reducción de los salarios reales. No obstante, el efecto en el empleo incrementa la reducción de la pobreza observada en Costa Rica y El Salvador después de introducir reformas únicamente en la política comercial, aunque se trata de un efecto marginal debido a que el precio de los bienes y servicios de consumo básico aumenta. En Honduras, las repercusiones de la devaluación en la pobreza son contrarias a las provocadas por las reformas de la política comercial debido al efecto contractivo mencionado y a la reducción de los salarios reales. El incremento de la desigualdad causado por las reformas de la política

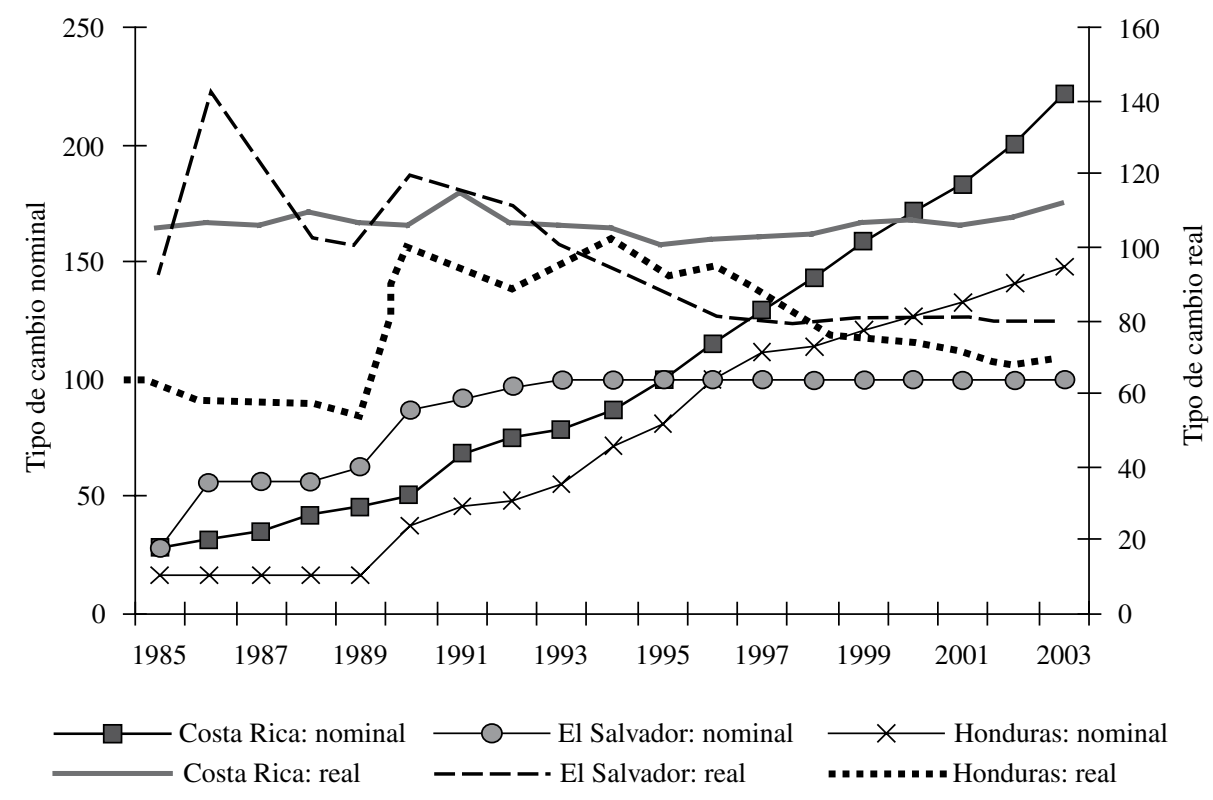

Fuente: Comisión Económica para América Latina y el Caribe (CEPAL). 
comercial se compensa con creces mediante la devaluación en Costa Rica y El Salvador, a raíz de la disminución de la demanda relativa de mano de obra calificada. En Honduras, el efecto adicional de la devaluación en la distribución del ingreso es prácticamente nulo en comparación con la situación en que solo se previeron reformas de la política comercial.

Los resultados de la simulación y los hechos reales examinados hasta ahora indican que solo en Costa Rica la política cambiaria reforzó los efectos favorables de las reformas de la política comercial y compensó los efectos negativos de las perturbaciones externas en el crecimiento de las exportaciones y la reducción de la pobreza. En los otros dos países ocurrió justamente lo contrario, pues la apreciación del tipo de cambio contrarrestó los efectos de dichas reformas en el aumento de las exportaciones y la pobreza.

\section{Reforma de la política comercial y productividad}

El éxito de las reformas de la política comercial también debe haber sido determinado por la medida en que ellas se acompañaron de un crecimiento de la productividad. De acuerdo con una descomposición de las variaciones en la productividad de la mano de obra presentada en Sánchez (2005), los trabajadores costarricenses fueron más productivos en la economía en general en los años noventa y en la agricultura en particular en el período 1990-2003. La misma descomposición indica que la evolución de la productividad de la mano de obra ha sido menos satisfactoria en El Salvador y Honduras, con la posible excepción del sector industrial del primero. Sin duda, la productividad de la mano de obra ha dependido de la disponibilidad de capital humano. El porcentaje de la población económicamente activa de 15 años de edad o más cuya escolaridad supera los 10 años es mucho mayor en Costa Rica que en El Salvador y Honduras, sobre todo en las zonas rurales, pues en 2002 este era del $19,6 \%$, en comparación con el $8,9 \%$ y el $4 \%$ en los otros dos países, respectivamente (CEPAL, 2003). En Costa Rica, las importaciones de materias primas y bienes de capital condujeron a la absorción de tecnologías perfeccionadas y a un mejor uso de la mano de obra calificada, incluso en la agricultura (Sánchez, 2004). Por otra parte, en El Salvador y Honduras la producción de los sectores de bienes no comerciables y de la industria maquiladora se ha caracterizado por el empleo de trabajadores de escasa calificación y bajos salarios, lo que ha dificultado el logro de un crecimiento sostenido de la productividad mediante el cambio tecnológico.

El modelo de equilibrio general computable utilizado no interioriza los beneficios dinámicos derivados del comercio y el crecimiento de la productividad total de los factores es exógeno. Hay pocas pruebas empíricas relativas a los factores que impulsan el aumento de la eficiencia inducido por el comercio en los tres países. Sin embargo, la simulación final de este trabajo tiene por objeto comprender mejor el efecto de las reformas de la política comercial cuando se acompañan de un incremento de la productividad. De esta forma, al simular las reformas de la política comercial se simuló también una alteración de la productividad consistente en un aumento del $5 \%$ de la productividad total de los factores, hipotéticamente provocado por un incremento correspondiente del $5 \%$ de la inversión extranjera directa y de la oferta relativa de mano de obra calificada.

La alteración de la productividad simulada no provoca mayores variaciones de los precios internos, pero brinda un notable estímulo a la producción que se ve rápidamente reflejado en la absorción interna. En general, fortalece los efectos distributivos favorables de las reformas de la política comercial y contrarresta los desfavorables (véase el cuadro 3). El modesto incremento del empleo provocado por las reformas de la política comercial se vuelve bastante considerable, sobre todo en El Salvador y Honduras, países en que existe mayor rezago en la dinámica productiva. Como resultado de ello, se observa una reducción mucho mayor de la pobreza, en especial en Costa Rica, donde la pobreza extrema disminuye marcadamente. La reducción de la pobreza es mucho más modesta en los otros dos países, pero los resultados y las tendencias reales sugieren que los factores que han impedido un alivio de la pobreza durante la implementación de las reformas de la política comercial son los déficits de productividad y capital humano. Las mermas de la productividad también producen algunos efectos indeseados. Los salarios reales se contraen en Honduras como resultado de un aumento más atípico del precio de los bienes no comerciables (en relación con los exportables). Además, las alteraciones de la productividad intensifican los efectos de desigualdad de las reformas de la política comercial simuladas en Costa Rica y El Salvador, algo que no ocurre en Honduras debido a la recomposición de la fuerza laboral. Este último resultado sugiere que para reducir la desigualdad de ingresos en Honduras será preciso aumentar de manera apreciable la inversión en capital humano. En cambio, la disponibilidad relativamente amplia y cada vez mayor de mano de obra calificada en Costa Rica ha contribuido a que el país pueda contrarrestar en parte los efectos distributivos desfavorables de las reformas de la política comercial y el crecimiento de la productividad. 


\section{V}

\section{Conclusiones y recomendaciones de política}

Las principales conclusiones de este trabajo se obtuvieron combinando los resultados de las simulaciones generadas mediante un modelo de equilibrio general computable con datos reales correspondientes al período 1990-2003. Se comprobó que, indudablemente, las reformas de la política comercial en Costa Rica, El Salvador y Honduras han incrementado la rentabilidad relativa de los sectores de exportación. Sin embargo, el crecimiento basado en las exportaciones y el "derrame" de los beneficios hacia los más pobres solo se han registrado en Costa Rica, debido sobre todo a tres razones.

En primer lugar, el sector exportador de Costa Rica se ha modernizado y diversificado notablemente, permitiendo que el país desarrolle la capacidad de generar divisas y de absorber las fluctuaciones desfavorables de precios en forma más satisfactoria. En El Salvador y Honduras, por otra parte, se optó por una mayor especialización en la industria maquiladora, que agrega poco valor a la economía debido a su ingente contenido de importación.

En segundo lugar, las entradas de remesas y capital privado, y en menor medida las bajas recurrentes de los precios mundiales de las exportaciones clave, han derivado en una apreciación del tipo de cambio real en El Salvador y Honduras, contrarrestando el efecto de las reformas de la política comercial en la rentabilidad relativa de los sectores exportadores. En Costa Rica, donde las remesas son menos importantes pero donde las corrientes de capital privado y de inversión extranjera directa han ejercido presión en el tipo de cambio real, se han utilizado satisfactoriamente las devaluaciones controladas para mantener un tipo de cambio real estable y competitivo, lo que ha sido fundamental para capitalizar los efectos deseados de las reformas de la política comercial.

En tercer lugar, en Costa Rica se han aprovechado la inversión extranjera directa y la mayor capacidad de generar divisas para absorber tecnologías que, unidas a una disponibilidad relativamente amplia de mano de obra calificada, han incrementado la productividad de la mano de obra, incluso en la agricultura. En El Salvador y Honduras, por el contrario, la falta de dinamismo de los sectores de bienes comerciables, la escasa diversificación de la agricultura y la mayor dependencia de la producción de la industria maquiladora — que emplea tecnologías tradicionales - se han traducido en una mayor demanda de mano de obra no calificada y baja generación de valor agregado.

Las reformas de la política comercial han empeorado la distribución del ingreso en Costa Rica, pero la pobreza ha disminuido porque la población rural, en particular, se ha visto favorecida por el mayor crecimiento de las exportaciones. Las reformas de la política comercial por sí solas explican en una mínima parte las tendencias relativas a la pobreza y la desigualdad del ingreso observadas en El Salvador y Honduras. No hay duda alguna de que las entradas de remesas han reducido la pobreza de esos dos países, pero la distribución del ingreso solo ha mejorado considerablemente en El Salvador, donde la mayoría de los receptores de las remesas vive en zonas rurales. En Honduras, en cambio, las remesas fluyen sobre todo a las áreas urbanas, de modo que, en términos relativos, empeora la situación de la población rural.

Las remesas de los trabajadores migrantes han aumentado la capacidad de consumo de los hogares en El Salvador y Honduras y han provocado una reasignación de los recursos desde los sectores de bienes comerciables a los de bienes no comerciables, pero casi no han incrementado la producción total. Esta inercia en términos de capacidad productiva y una mayor apreciación del tipo de cambio real podrían persistir a largo plazo, habida cuenta de que probablemente continuarán llegando remesas a estos países. Este "mal de las remesas" podría limitar aún más la creación de capacidad productiva para generar empleo a lo largo del tiempo, sobre todo en los sectores exportadores.

Estas conclusiones apuntan a la necesidad de aplicar medidas de política para que los tres países, sobre todo El Salvador y Honduras, puedan aumentar la rentabilidad relativa de sus exportaciones durante la liberalización comercial en el marco del Tratado de Libre Comercio entre República Dominicana, Centroamérica y los Estados Unidos y de otros acuerdos comerciales. La diversificación de las exportaciones, el cambio tecnológico, la inversión en capital humano y el aumento de la productividad son requisitos para cosechar los beneficios de una mayor liberalización comercial. En particular, debería darse prioridad a la diversificación de las exportaciones, pues reduce la exposición a las fluctuaciones de precios de las exportaciones que socavan 
los efectos deseados de la liberalización comercial. Se necesitarán políticas para contrarrestar las presiones al alza del tipo de cambio provocadas por el aumento de las corrientes de remesas y el deterioro de los términos de intercambio que tendrán lugar cuando disminuya la demanda de bienes y servicios de exportación, en el marco de una desaceleración de la economía mundial caracterizada por los precios sostenidamente elevados del petróleo. El desafío consistirá en elaborar políticas de promoción de las exportaciones admisibles de acuerdo con las normas de la omc y que no pongan en peligro las finanzas públicas. Costa Rica y Honduras todavía pueden recurrir a la política cambiaria, no así El Salvador mientras su economía siga estando dolarizada. La elaboración de planes de inversión rentable de las remesas será fundamental en países como El Salvador y Honduras, en particular si mediante ellos se logra aumentar la producción para la exportación y el empleo.
Acevedo, C. (2004): El Salvador: efectos del crecimiento exportador sobre la pobreza y la distribución del ingreso, en E. Ganuza, S. Morley y otros (comps.), ¿Quién se beneficia del libre comercio? Promoción de exportaciones y pobreza en América Latina y el Caribe en los 90, Bogotá, D.C., Programa de las Naciones Unidas para el Desarrollo (PNUD)/AlfaOmega.

Almeida dos Reis, J.G. y R. Paes de Barros (1991): Wage inequality and the distribution of education: a study of the evolution of regional differences in inequality in metropolitan Brazil, Journal of Development Economics, vol. 36, No 1, Amsterdam, Elsevier.

CEPAL (Comisión Económica para América Latina y el Caribe) (2003): Panorama social de América Latina 2002-2003, LC/G.2209-P, Santiago de Chile. Publicación de las Naciones Unidas, $\mathrm{N}^{\circ}$ de venta: S.03.II.G.185.

(2006): Panorama social de América Latina 2006, LC/G.2326-P, Santiago de Chile. Publicación de las Naciones Unidas, $\mathrm{N}^{\circ}$ de venta: S.06.II.G.133.

Cox-Edwards, A. y S. Edwards (1994): Labour market distortions and structural adjustment in developing countries, en S. Horton, R. Kanbur y D. Mazumdar (comps.), Labour Markets in an Era of Adjustment, Washington, D.C., Banco Mundial.

Cuesta, J. y M.V. Sánchez (2004): Honduras: crecimiento exportador, distribución y pobreza, en E. Ganuza, S. Morley y otros (comps.), ¿Quién se beneficia del libre comercio? Promoción de exportaciones y pobreza en América Latina y el Caribe en los 90, Bogotá, D.C., Programa de las Naciones Unidas para el Desarrollo (PNUD)/AlfaOmega.

Dervis, K., J. de Melo y S. Robinson (1982): General Equilibrium Models for Development Policy, Cambridge, Cambridge University Press.

Edwards, S. (1988): Terms of trade, tariffs, and labour market adjustment in developing countries, World Bank Economic Review, vol. 2, $\mathrm{N}^{\circ}$ 2, Washington, D.C., Banco Mundial.

Evans, H.D. (1989): Comparative Advantage and Growth: Trade and Development in Theory and Practice, Wheatsheaf, Brighton.

Ganuza, E., R. Paes de Barros y R. Vos (2002): Labour market adjustment, poverty and inequality during liberalisation, en R. Vos, L. Taylor y R. Paes de Barros (comps.), Economic Liberalisation, Distribution and Poverty: Latin America in the 1990s, Cheltenham, Edward Elgar.

Ganuza, E., S. Morley y otros (comps.) (2004): ¿Quién se beneficia del libre comercio? Promoción de exportaciones y pobreza en
América Latina y el Caribe en los 90, Bogotá, D.C., Programa de las Naciones Unidas para el Desarrollo (PNUD)/AlfaOmega.

Löfgren, H., R. Lee y S. Robinson (2002): A standard computable general equilibrium (CGE) model in GAMS, Microcomputers in Policy Research 5, Washington, D.C., Instituto Internacional de Investigaciones sobre Políticas Alimentarias.

Robinson, S. (1989): Multisector models, en H. Chenery y T.N Srinivasan (comps.), Handbook of Development Economics, vol. 2, Amsterdam, Elsevier.

Salvatore, D. (1995): International Economics, Nueva York, PrenticeHall.

Sánchez, M.V. (2004): Rising Inequality and Falling Poverty in Costa Rica's Agriculture during Trade Reform. A Macro-micro General Equilibrium Analysis, Maastricht, Shaker.

(2005): Reformas económicas, régimen cambiario y choques externos: efectos en el desarrollo económico, la desigualdad y la pobreza en Costa Rica, El Salvador y Honduras, serie Estudios y perspectivas, $\mathrm{N}^{\circ} 36$, LC/L.2370-P, México, D.F., Sede Subregional de la CEPAL en México. Publicación de las Naciones Unidas, $\mathrm{N}^{\mathrm{o}}$ de venta: 2.05.II.G.111.

(2007): Liberalización comercial en el marco del DRCAFTA: efectos en el crecimiento, la pobreza y la desigualdad en Costa Rica, serie Estudios y perspectivas, $\mathrm{N}^{\circ} 80$, LC/ MEX/L.771/Rev.1, México, D.F., Sede Subregional de la CEPAL en México. Publicación de las Naciones Unidas, $\mathrm{N}^{\circ}$ de venta: S.07.II.G.48.

Sánchez, M.V. y P. Sauma (2006): Costa Rica - export-orientation and its effect on growth, inequality and poverty, en R. Vos, E. Ganuza y otros (comps.), Who Gains from Free Trade? Export-led growth, inequality and poverty in Latin America, Nueva York, Routledge.

Segovia, A. (1998): Cambio estructural, políticas macroeconómicas y pobreza en El Salvador, en E. Ganuza, L. Taylor y S. Morley (comps.), Política macroeconómica y pobreza en América Latina y el Caribe, Madrid, Mundi Press.

Vos, R., E. Ganuza y otros (comps.) (2006): Who Gains from Free Trade? Export-led Growth, Inequality and Poverty in Latin America, Nueva York, Routledge.

Wood, A. (1994): North-South Trade, Employment and Inequality: Changing Fortunes in a Skill-Driven World, Oxford, Clarendon Press. 